\title{
Nav1.7 Sodium Channel Isoform is Expressed in Growth Cones of Hippocampal Neurons in Culture
}

\author{
Valeria Bonetti $^{1,2}$, Jeismar Carballo ${ }^{1,2}$, Lisbeth Garcia ${ }^{1}$, Elizabeth Gómez ${ }^{1}$ and Marines Longart ${ }^{{ }^{*}}$ \\ ${ }^{1}$ Unidad de Neurociencias, Instituto de Estudios Avanzados (IDEA), Caracas 1015A, Venezuela \\ ${ }^{2}$ Departamento de Biología Celular, Universidad Simón Bolívar, Caracas 1081A, Venezuela
}

"Corresponding author: Marines Longart, Unidad de Neurociencias, Instituto de Estudios Avanzados (IDEA), Apartado 17606, Caracas 1015A, Venezuela, Tel: +58-212-9035191, Fax: +58-212-9035118; E-mail: mlongart87@gmail.com

Received date: May 17, 2016; Accepted date: June 03, 2016; Published date: June 15, 2016

Copyright: $\odot 2016$ Bonetti V, et al. This is an open-access article distributed under the terms of the Creative Commons Attribution License, which permits unrestricted use, distribution, and reproduction in any medium, provided the original author and source are credited.

\begin{abstract}
Voltage Dependent Sodium Channels (VDSC) is fundamental for neuronal excitability and action potential propagation. There is a differential expression of the VDSC isoforms in different regions within the Central (CNS) and Peripheral Nervous System (PNS). The different isoforms $\left(\mathrm{Na}_{v} 1.1-\mathrm{Na}_{v} 1.9\right)$ are widely expressed within the nervous system during specific developmental stages; however, the precise subcellular distribution for some isoforms is still incomplete. VDSC are important therapeutic targets for a wide variety of pathophysiological conditions, including chronic pain, cardiac arrhythmia, and epilepsy. Studies on the genetic basis underlying several striking human phenotypes have revealed the importance of $\mathrm{Na}_{\mathrm{v}} 1.7$ in pain signalling pathways and as a therapeutic target for treatment of chronic pain. Given that $\mathrm{Na}_{\vee} 1.7$ expression in CNS has not been precisely addressed, and that the determination of its precise location is important to understand its function within neurons, we attempted to study the Nav1.7 subcellular localization in hippocampal neurons in culture by immunofluorescence. On the other hand, we studied the $\mathrm{Na}_{\mathrm{V}} 1.2$ subcellular localization and compared its expression pattern with $\mathrm{Na}_{\mathrm{V}} 1.7 . \mathrm{Na}_{\mathrm{V}} 1.2$ is a Tetrodotoxin (TTX)-sensitive channel, predominantly expressed in the central nervous system and its subcellular distribution has been widely studied in central neurons. When we compared $\mathrm{Na}_{\mathrm{V}} 1.2$ and $\mathrm{Na}_{\mathrm{V}} 1.7$ we observed a distinctive subcellular localization for these two isoforms. Additionally, using a PanNa $\mathrm{V}_{\mathrm{V}}$ antibody, which recognizes all sodium channel isoforms, we observed that PanNav signal overlapped $\mathrm{Na}_{v} 1.2$ and $\mathrm{Na}_{\vee} 1.7$ specific signals. PanNav labeled the Axon Initial Segment (AIS), cell bodies and neurites. Nav1.2 specific signal was mainly observed in the AIS, soma, dendrites and Golgi apparatus; while $\mathrm{Na}_{v} 1.7$ mainly was present in soma, axons and growth cones. Our findings describing $\mathrm{Na}_{\mathrm{v}} 1.7$ in growth cones represent a new subcellular localization for this isoform and provide new evidences that suggest additional roles in neuronal functioning within the CNS.
\end{abstract}

Keywords: Sodium channels; Subcellular localization; Hippocampal neurons, Axons; Dendrites; Growth cones

\section{Introduction}

Voltage Dependent Sodium Channels (VDSC) are fundamental for neuronal excitability and action potential propagation, through modulation of sodium influx during the initial phase of action potentials [1,2]. So far, nine a subunits isoforms $\left(\mathrm{Na}_{\mathrm{v}} 1.1-\mathrm{Na}_{\mathrm{v}} 1.9\right)$ have been reported. These are widely expressed within the nervous system as heteromeric transmembrane complexes of a pore forming structure [1,3-8]. Alpha $(\alpha)$ subunits are associated with auxiliary $\beta$ subunits, which modulate channel functioning [9-11].

Neuronal excitability allows neurons to receive, process and transmit information to other cells in the form of action potentials; these functions are performed by anatomically distinct regions of neuronal cells, such as dendrites and axons. Space-time localization of sodium channel isoforms has been widely studied in the nervous system. Regarding their temporal expression, it has been reported, that sodium channels are present through different stages of development. VDSC are expressed in early stages at the neural plate of 10 day rat embryos [12,13], in embryonic and early postnatal stages (i.e., $\mathrm{Na}_{\mathrm{v}} 1.3$ ), during the entire embryonic development (i.e., $\mathrm{Na}_{\mathrm{v}} 1.2$ ) and in late postnatal stages (i.e., $\mathrm{Na}_{\mathrm{v}} 1.1$ ) [14-15].
Regarding the regional localization of the VDSC isoforms, several studies have reported that $\mathrm{Na}_{\mathrm{v}} 1.1, \mathrm{Na}_{\mathrm{v}} 1.2$, and $\mathrm{Na}_{\mathrm{v}} 1.3$ subtypes are expressed in the CNS. $\mathrm{Na}_{\mathrm{v}} 1.6$ is expressed in both PNS and CNS, whereas $\mathrm{Na}_{\mathrm{v}} 1.7, \mathrm{Na}_{\mathrm{v}} 1.8$, and $\mathrm{Na}_{\mathrm{v}} 1.9$ are mostly restricted to the PNS $[2,12]$. Other reports have shown a differential expression of the VDSC isoforms in different tissues within the CNS; for example, $\mathrm{Na}_{\mathrm{V}} 1.1$ and $\mathrm{Na}_{\mathrm{V}} 1.2$ isoforms were overall present in the brain, mainly in hippocampus, cerebral cortex and cerebellum. VDSC isoforms are also predominantly expressed in other tissues; for instance, $\mathrm{Na}_{\mathrm{V}} 1.4$ is the major isoform in the skeletal muscle, $\mathrm{Na}_{\mathrm{V}} 1.5$ is present in cardiac muscle and embryonic skeletal muscle $[10,13]$. On the other hand, some of these isoforms have also been reported in the CNS. That is the case for $\mathrm{Na}_{\mathrm{V}} 1.5$, which is also observed in the brain [14] and $\mathrm{Na}_{\mathrm{V}} 1.7$, for which the mRNA was detected in the CNS, in mouse and rat brain [15]; and more specifically at the hippocampus [16].

VDSC are important therapeutic targets for a wide variety of pathophysiological conditions, including chronic pain, cardiac arrhythmia, and epilepsy [17]. $\mathrm{Na}_{\mathrm{v}} 1.7$ channels are preferentially expressed in peripheral neurons, mainly at the terminals of sensory neurons, within the neuronal soma of DRGs, and at central terminals of neuronal afferents in the superficial laminae of the spinal cord $[18,19]$.

Regarding the precise subcellular localization, $\mathrm{Na}_{\mathrm{V}} 1.2$ has been found in axons, terminals [20-25] and dendrites [26]; although other 
authors reported that very little $\mathrm{Na}_{\mathrm{V}} 1.2$ was observed on the somatic or dendritic membrane [24]. On the other hand, $\mathrm{Na}_{\mathrm{V}} 1.2$ is seen at high densities at the Axonal Initial Segment (AIS) [27] and during the formation of the nodes of Ranvier [28], but when the nodes are maturing $\mathrm{Na}_{\mathrm{V}} 1.2$ was observed in only a small subpopulation of these [29].

Despite the progress made about determining the localization of these isoforms, there are still uncertainties regarding the precise regional localization of some isoforms, i.e., $\mathrm{Na}_{V}$ 1.7. The precise subcellular localization of this isoform is largely unknown; more specifically, the protein expression in the CNS is an actual matter of debate. Therefore, to gain more insight in this matter, in the present work we studied the subcellular localization of $\mathrm{Na}_{\mathrm{V}} 1.7$ isoform in hippocampal neurons and compared with the protein expression pattern of $\mathrm{Na}_{\mathrm{V}} 1.2$, for which the subcellular localization has been well characterized. Thus, we performed immunofluorescence analysis using a generic VDSC antibody for all members of $\mathrm{Na}_{V} 1$ subfamily $\left(\mathrm{PanNa}_{\mathrm{V}}\right)$ and specific antibodies for $\mathrm{Na}_{V} 1.2$ and $\mathrm{Na}_{V} 1.7$ isoforms. Important findings of this study showed a distinctive subcellular localization of these sodium channel isoforms. Specifically, a variable density of the different VDSC isoforms are differentially distributed in cell bodies, dendrites, AIS, neurite terminals and axons, which might be related to the generation of action potentials in those cellular compartments. Among the most relevant findings in this study is the localization of $\mathrm{Na}_{V} 1.7$ in growth cones and $\mathrm{Na}_{\mathrm{V}} 1.2$ in Golgi. These results provide new evidences that support distinctive and additional functions for sodium channels isoforms, which might have important roles in neuronal differentiation and functioning.

\section{Materials and Methods}

\begin{abstract}
Antibodies
Primary antibodies for the immunocytochemistry were: rabbit antiPanNa $a_{V}$, which recognizes all a subunits of $\mathrm{Na}_{V} 1$ subfamily (1:200; AB5210, Chemicon-MIllipore, Billerica, Massachusetts, USA); rabbit anti-Na $\mathrm{N}_{\mathrm{V}} 1.2$ and rabbit anti-Na $\mathrm{Na}_{\mathrm{V}} 1.7$ (1:200; AB5390 and AB5206, respectively; Chemicon-Millipore). Other antibodies were: mouse antiGM130, that recognizes cis-cisternae of Golgi apparatus (1:100; 610822, BD Biosciences, San Diego, California, USA); mouse antiMAP2, that recognizes dendrites (1:5000; M4403, Sigma, St Louis, Missouri, USA) and mouse anti-Hypophosphorylated Neurofilament $\mathrm{H}$ antibody SMI35, which recognizes axons (1:5000; ab24564. Abcam, Cambridge, MA, USA). Secondary antibodies were: Goat anti-mouse Alexa Fluor 488 (1:200), goat anti-rabbit Alexa Fluor 594 (1:600) (Invitrogen). Non immunological probes were F-actin probe conjugated to a fluorescent dye, Rhodamine Phalloidin (1:40; Invitrogen) and DAPI (1:10,000; BD Biosciences).
\end{abstract}

\section{Animals}

Sprague-Dawley 19 day embryos (E19) were used to generate neuronal cultures. Embryos were removed by caesarian section after the mother had been sacrificed by $\mathrm{CO}_{2}$ inhalation and decapitation. Animals were maintained and sacrificed following the regulations from the Instituto de Estudios Avanzados (IDEA), in accordance with the National Institutes of Health Guide, for the Care and Use of Laboratory Animals (NIH Publications No. 80-23, revised 1996). Care was taken to use the minimal amount of animals and all precautions were taken to minimize any suffering.

\section{Neuronal primary cultures}

Dissociated hippocampal cultures were prepared from embryonic day 19 (E19) Sprague-Dawley rats, as previously described [30,31]. Briefly, rat hippocampus were dissected and then washed three times with cold Hank's Balanced Salt Solution (HBSS) supplemented with 9.5 $\mathrm{mM}$ of HEPES and 1\% Penicillin/Streptomycin (Sigma, St. Louis, MO, USA). After that, $0.3 \%$ of trypsin was added to HBSS. This solution was incubated for $15 \mathrm{~min}$ at $37^{\circ} \mathrm{C}$. Cells were resuspended in $4 \mathrm{ml}$ of Neurobasal medium supplemented with B-27. Cells were plated at a final concentration of $5 \times 10^{4} \mathrm{cell} / \mathrm{ml}$ on $12 \mathrm{~mm}$ coverslips, pretreated with Poly-D-Lysine/Laminin $(0.0375 \mathrm{mg} / \mathrm{ml}$ of PDL and $0.0025 \mathrm{mg} / \mathrm{ml}$ of Laminin). Cell cultures were maintained in incubator at $5 \% \mathrm{CO}_{2}$ and $37^{\circ} \mathrm{C}$ from 2 through 15 days. All reagents, unless indicated, in this section were from Gibco- Invitrogen (Carlsbad, CA, USA).

\section{Immunocytochemistry}

After removal of culture medium, neurons were fixed with $4 \%$ paraformaldehyde in PBS for $20 \mathrm{~min}$. Then, cells were permeabilized with $0.25 \%$ Triton-X100 in PBS for $10 \mathrm{~min}$. Cells were blocked with $10 \%$ Normal Goat Serum (NGS, Sigma) in PBS for 1 hour, and then treated with primary antibodies in $2 \%$ NGS in PBS, overnight, at $4^{\circ} \mathrm{C}$. Next day, secondary antibodies and DAPI were diluted in $2 \%$ NGS in PBS and incubated for 1 hour in the dark. Coverslips were mounted in Mowiol-Dabco. All incubations, unless specified, were done at room temperature.

\section{Staining with Rhodamine Phalloidin}

For staining of the cytoskeleton we used the non-immunological probe Rhodamine-Phalloidin as performed in other studies [30]. Briefly, after medium removal, cells were incubated with a mixed solution (3.7\% formaldehyde, $0.075 \%$ glutaraldehyde, $1 \%$ Triton X-100, in $\mathrm{PBS}$ ), pre-heated to $37^{\circ} \mathrm{C}$ for $2 \mathrm{~min}$ and then incubated with a fixation solution (3.7\% formaldehyde, $0.075 \%$ glutaraldehyde, in PBS) for $15 \mathrm{~min}$; finally, cells were incubated with a permeabilization solution (1\% Triton X-100, in PBS) for 30 minutes. Coverslips were stored in PBS1X at $4^{\circ} \mathrm{C}$ until the day of the immunostaining. Blocking and the rest of the procedure were performed as described above.

\section{Imaging}

Cells were imaged on an Axio Observer Z1 fluorescent inverted microscope (Carl Zeiss, Jena, Germany) and controlled by Metamorph software (Molecular Devices. California, USA). Filters used were 488049 (excitation 365nm, emission 445/50 nm), 489038 (excitation $470 / 40 \mathrm{~nm}$ emission 525/50) and 488020 (excitation 546/12 nm emission 575-640). Objectives were Plan-Apochromat immersion oil 100X/1.4 and Plan-NeoFluar immersion oil 40X/1.3. Images were acquired with digital camera (CCD Cool SNAP HQ2). Image analysis and processing were performed with NIH ImageJ software $(\mathrm{NIH}$, Bethesda, MD). Figures were prepared in Adobe Photoshop CS2 and minor adjustment of brightness and contrast were performed.

\section{Results}

\section{Sodium channel isoforms $\mathrm{Na}_{\mathrm{v}} 1.2$ and $\mathrm{Na}_{\mathrm{v}} 1.7$ show distinctive subcellular localization in hippocampal neurons in culture}

In order to study the subcellular localization of sodium channels, we performed triple labeling experiments using an antibody against 
Citation: Bonetti V, Carballo J, Garcia L, Gómez E, Longart M (2016) Nav1.7 Sodium Channel Isoform is Expressed in Growth Cones of Hippocampal Neurons in Culture. J Epilepsy 2: 106. doi:10.4172/2472-0895.1000106

Page 3 of 7

sodium channels, an antibody (or non-immunological probe) for a cellular compartment and the non-immunological probe DAPI. For one of these experiments neurons cultured for 6 days in vitro (DIV) and were labeled either with $\mathrm{PanNa}_{\mathrm{V}}, \mathrm{Na}_{\mathrm{V}} 1.2$ or $\mathrm{Na}_{\mathrm{V}} 1.7$, MAP2 (antibody that specifically recognizes neuronal cell bodies and dendrites) and counterstained with DAPI. PanNa $a_{v}$ antibody, mostly labeled the soma, and a segment in the neurites, positive for $\mathrm{PanNa}_{\mathrm{V}}$ and negative for MAP2 (arrows, Figures 1a-1c). In these cases, the $\mathrm{PanNa}_{\mathrm{v}}$ staining began where the MAP2 staining ended. This structure, which is positive for $\mathrm{PanNa}_{\mathrm{V}}$ and negative for MAP2 [32,33], represents the AIS. We also observed $\mathrm{PanNa}_{\mathrm{v}}$ isoforms in dendritic shafts (Figure 1); however, we could not observe labeling in axons or axonal tips. Similar to the observed with $\mathrm{PanNa}_{\mathrm{V}}$, the $\mathrm{Na}_{\mathrm{V}} 1.2$ labeling showed a neurite segment, positive for $\mathrm{Na}_{\mathrm{V}} 1.2$ and negative for MAP2 (arrows, Figures 1d-1f), likely corresponding to the AIS. $\mathrm{Na}_{\mathrm{V}} 1.2$ was occasionally observed in few dendrites, mainly in their proximal segments, whereas $\mathrm{Na}_{\mathrm{V}} 1.2$ labeling in axons in very few cases was very weak or non-existent (data not shown). On the other hand, $\mathrm{Na}_{V} 1.7$ labeling was mainly observed in the proximal part of principal dendrites (arrows, Figures 1g-1i). Interestingly, this isoform was not observed at the AIS, however a distinctive and strong labeling was observed at the endings of small branches coming out of principal dendrites (asterisks, Figures 1g-1i).
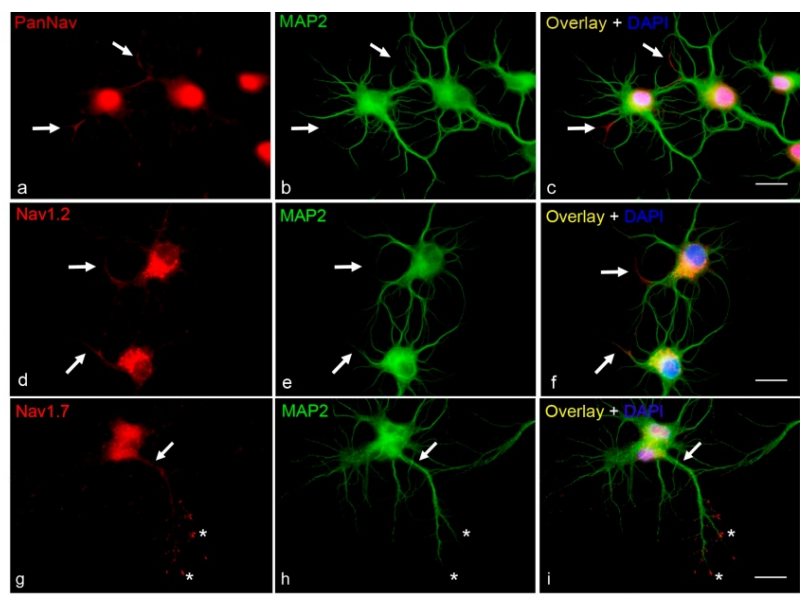

Figure 1: Localization of $\mathrm{Na}_{\mathrm{v}} 1.2$ and $\mathrm{Na}_{\mathrm{v}} 1.7$ in hippocampal neurons. Upper panels show the immunostaining of DIV 6 hippocampal neurons using a PanNa $a_{V}$ antibody (red), MAP2 antibody (green) and DAPI (Blue). PanNa $\mathrm{V}_{\mathrm{V}}$ signal is observed mostly in the soma and in the AIS, arrows indicate a process labeled with PanNa $\mathrm{V}_{\mathrm{V}}$ but not with MAP2 (AIS) (a-c). Middle panels show the immunostaining of DIV 6 hippocampal neurons labeled with $\mathrm{Na}_{\mathrm{v}} 1.2$ antibody, MAP2 antibody (green) and DAPI (Blue). Nav1.2 is mostly seen in soma, AIS and some neuronal processes. Arrows indicate the AIS (d-f), $33.33 \%$ of the cells showed staining for $\mathrm{Na}_{\mathrm{v}} 1.2$ at the AIS. Lower panels show the immunostaining of DIV 6 hippocampal neurons labeled with $\mathrm{Na}_{\mathrm{v}} 1.7$ antibody, MAP2 antibody (green) and DAPI (Blue). $\mathrm{Na}_{\mathrm{v}} 1.7$ is mainly observed at proximal part of processes (arrows) and in terminals (asterisks) (gi). Scale bars $=20 \mu \mathrm{m}$.

\section{Sodium channel $\mathrm{Na}_{\mathrm{V}} 1.7$ isoform is located in axons and growth cones}

$\mathrm{Na}_{\mathrm{V}} 1.7$, at DIV2, was observed mainly in cell bodies, short neurites (dendrites) positive for MAP2, (arrows, Figures 2A-2C) and along the longest neurite (diffuse staining, arrowheads, Figures 2A-2c), which usually represents the axon $[33,34]$, although at this stage this longest neurite is also labeled with MAP2 (arrowheads, Figures 2A-2C) [35]. Interestingly, a stronger and more defined labeling for $\mathrm{Na}_{\mathrm{V}} 1.7$ was observed in neurite terminals (boxed area, Figures 2A-2C). Taking in consideration the $\mathrm{Na}_{V} 1.7$ localization in neurite terminals, it was important to know whether or not those structures were growth cones; to confirm that, we performed immunostaing experiments in DIV 2 neurons with $\mathrm{Na}_{\mathrm{V}} 1.7$ antibody and Rhodamine Phalloidin (probe that labels the actin filaments concentrated in growth cones). Indeed, $\mathrm{Na}_{V} 1.7$ was observed in growth cones with a good overlapping with the actin filaments (arrows and boxed area, Figures 2B and 2C). In older cultures, like DIV 9 or 15, the amount of neurite terminals labeled with $\mathrm{Na}_{\mathrm{V}} 1.7$ decreased as compared to younger neuronal cultures (data not shown).
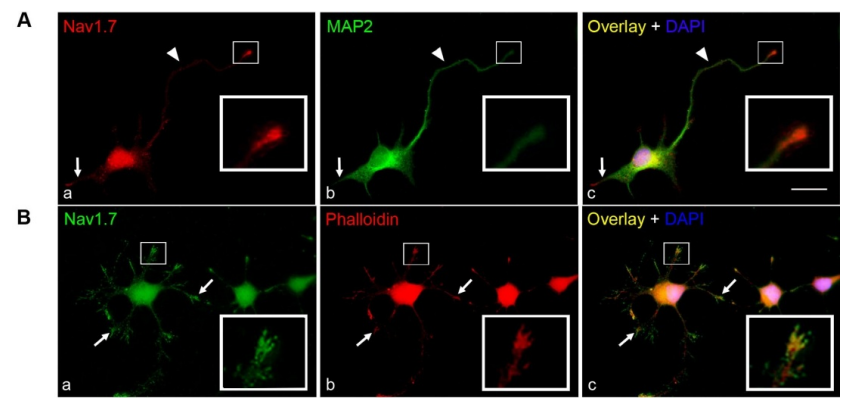

Figure 2: Analysis of $\mathrm{Na}_{V} 1.7$ localization in neurites. A) Immunostaining of DIV 2 hippocampal neurons using $\mathrm{Na}_{\mathrm{V}} 1.7$ antibody (red), MAP2 antibody (green) and DAPI (blue). $\mathrm{Na}_{\mathrm{V}} 1.7$ was localized in soma, neurites and terminals: dendrites (arrows, ac) and axon-like processes (arrowheads, a-c). Terminal of the axonlike process is shown enlarged in the boxed area $(\mathrm{a}-\mathrm{c}) . \mathrm{B})$ Immunostaining of DIV 2 hippocampal neurons with $\mathrm{Na}_{\mathrm{V}} 1.7$ antibody (green), Phalloidin (red) and DAPI (blue). Localization of $\mathrm{Na}_{V} 1.7$ is observed in neurite terminals. The overlapping of $\mathrm{Na}_{V} 1.7$ with Phalloidin staining, used to identify growth cones, is indicated by arrows (a-c) and it is shown in the enlarged boxed area, 59.09\% of the neurons showed staining for $\mathrm{Na}_{\mathrm{v}} 1.7$ at the growth cones. Scale bars $=20 \mu \mathrm{m}$.

As already mentioned, at DIV2, we observed $\mathrm{Na}_{\mathrm{v}} 1.7$ in most of the neurons, at the tip of the longest neurite. Then we performed double labeling with the axonal marker (SMI 35) at DIV2 and DIV6 (Figure 3 ). In young neurons (DIV2), the longest neurite was labeled with SMI 35 (arrowhead, Figures 3a-3c) and the neurites positive for the axonal marker showed a weaker staining for $\mathrm{Na}_{\mathrm{v}} 1.7$. Again, the shorter processes (neurites also labeled with MAP2), were labeled with the axonal marker and $\mathrm{Na}_{\mathrm{v}} 1.7$ (arrows, Figures 3a-3c). Again, we observed $\mathrm{Na}_{\mathrm{v}} 1.7$ ant the ends of the neurites (asterisks, Figure 3a-3c). At DIV6, $\mathrm{Na}_{\mathrm{v}} 1.7$ labeling became more intense in the axonal processes (arrowheads, Figures 3d-3f). At this age was very difficult to observe the axon terminals and the $\mathrm{Na}_{\mathrm{v}} 1.7$ labeling at the extremes of these, however the $\mathrm{Na}_{\mathrm{v}} 1.7$ labeling was very intense at the ends of the shorter processes (arrows, Figures 3d-3f). 
Citation: Bonetti V, Carballo J, Garcia L, Gómez E, Longart M (2016) Nav1.7 Sodium Channel Isoform is Expressed in Growth Cones of Hippocampal Neurons in Culture. J Epilepsy 2: 106. doi:10.4172/2472-0895.1000106
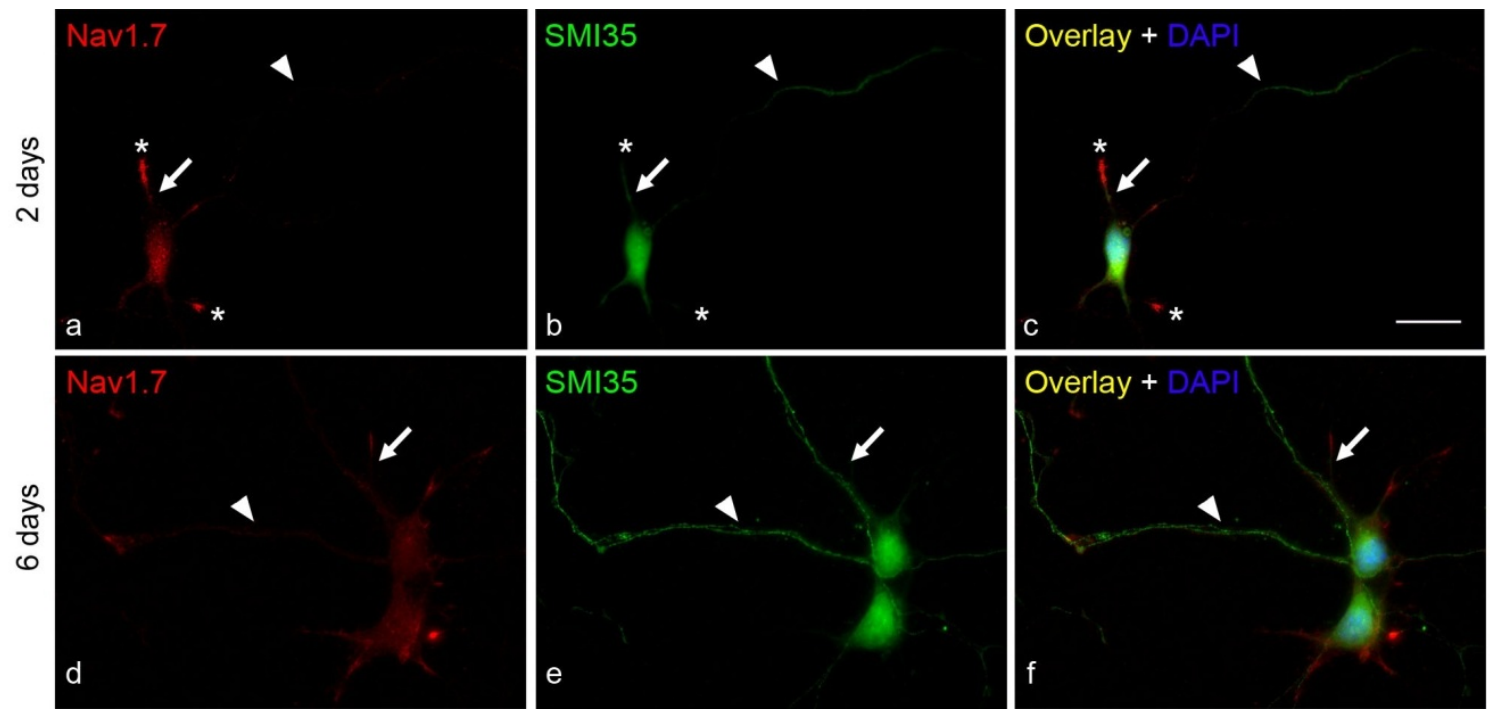

Figure 3: Analysis of $\mathrm{Na}_{V} 1.7$ localization in axons. Immunostaining of DIV 2 and DIV 6 hippocampal neurons with Na 1.7 (red), SMI35 (green) and DAPI (Blue). At Div 2, a weak signal for $\mathrm{Na}_{\mathrm{V}} 1.7$ in the longest neurite which overlaps the axonal marker (SMI35) is observed (arrowheads, a-c), while shorter neurites labeled with the axonal marker, are also labeled with $\mathrm{Na}_{\mathrm{V}} 1.7$ (arrows, a-c); neurite terminals are labeled with $\mathrm{Na}_{\mathrm{V}} 1.7$ (asterisks, a-c). At DIV 6, is better observed the overlap between $\mathrm{Na}_{\mathrm{V}} 1.7$ and SMI35 (arrowheads, d-f) and short branches in neurites are single labeled with $\mathrm{Na}_{\mathrm{V}} 1.7$ antibody (arrows, d-f). Scale bars $=20 \mu \mathrm{m}$.

\section{Analysis of the subcellular localization of $\mathrm{Na}_{\mathrm{v}} 1.2$ and $\mathrm{Na}_{\mathrm{v}} 1.7$ in soma and Golgi apparatus}

As shown in Figure 1, the signal of $\mathrm{Na}_{\mathrm{V}} 1.2$ at the soma showed an overlap with MAP2 and was excluded from the nuclear area. $\mathrm{Na}_{\mathrm{V}} 1.2$ expression in the cell bodies increased while neurons were maturing (DIV2-6, Figures 4a-4f). In this sense, in order to precisely identify areas within the cell bodies, that were expressing $\mathrm{Na}_{V} 1.2$, we performed immunofluorescent experiments with $\mathrm{Na}_{\mathrm{V}} 1.2$, GM130 and DAPI with DIV 2-6 neurons. In these experiments, specifically at DIV 2 , we observed a low signal for $\mathrm{Na}_{\mathrm{V}} 1.2$ which showed a partial overlap with the GM130 labeling (arrows, Figures 4a-4c). At DIV 6 we observed a stronger signal for $\mathrm{Na}_{\mathrm{V}} 1.2$, which showed a broader and almost perfect overlapping with GM130 (arrows, Figures 4d-4f).

This overlapping remained at DIV 15 (data not shown). At the same time, we studied the subcellular distribution of $\mathrm{Na}_{V} 1.7$ in soma. At DIV 2, it was already observed a major concentration of $\mathrm{Na}_{\mathrm{V}} 1.7$ labeling in the cell bodies. Regarding the precise $\mathrm{Na}_{\mathrm{v}} 1.7$ subcellular localization within the cell bodies, our results showed that $\mathrm{Na}_{V} 1.7$ signal at DIV 2 was stronger and occupied a broader area of the cell body, in comparison to $\mathrm{Na}_{\mathrm{v}} 1.2$. On the other hand, and different from the observed with $\mathrm{Na}_{\mathrm{v}} 1.2$, areas of overlapping between $\mathrm{Na}_{V} 1.7$ and Golgi there were almost non-existent and the Golgi labeling was more defined than the $\mathrm{Na}_{\mathrm{v}} 1.7$ labeling (arrows, Figures 5a-5c). At DIV 6, it was observed a broader labeling pattern for $\mathrm{Na}_{\mathrm{v}} 1.7$, although the extent of the overlapping for Golgi and $\mathrm{Na}_{\mathrm{v}} 1.7$ signals were difficult to determine. The $\mathrm{Na}_{\mathrm{v}} 1.7$ labeling was observed in areas where the ER is usually located (arrows, Figures 5d-5f).

\section{Discussion}

Cellular differentiation, functional specification and sodium channel activity are crucial for neuronal development; therefore, one of the critical aspects to understand the functioning of the nervous system is the precise subcellular localization of proteins involved in these processes. Voltage-Dependent Sodium Channels (VDSC) are responsible for action potential initiation and propagation in electrically excitable cells. One of their major physiological roles is to generate action potentials at the axon hillock/initial segment to ensure propagation along the axons and towards the nerve terminals $[1,3]$.

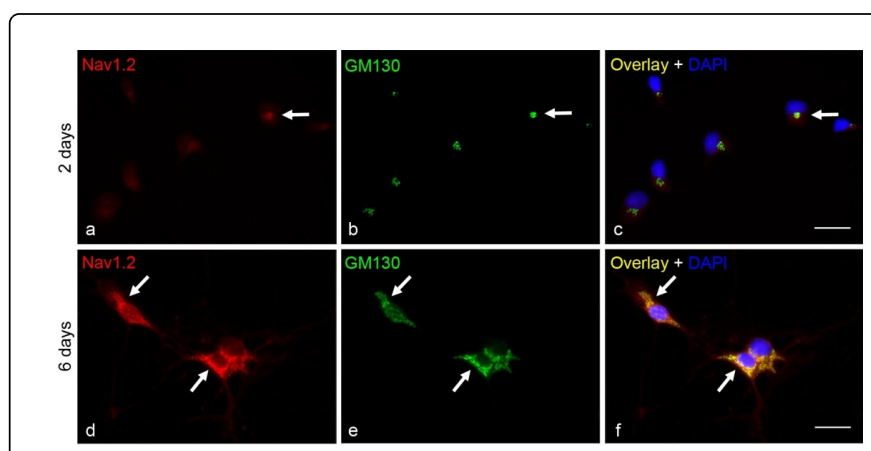

Figure 4: Analysis of $\mathrm{Na}_{\mathrm{V}} 1.2$ localization in Golgi apparatus. Immunostaining of DIV 2 and DIV 6 and hippocampal neurons using $\mathrm{Na}_{\mathrm{V}} 1.2$ antibody (red), GM130 antibody (green) and DAPI (Blue). Observe the low signal of $\mathrm{Na}_{\mathrm{V}} 1.2$ in DIV 2 neurons (a-c). At DIV2 there is a light staining of $\mathrm{Na}_{\mathrm{V}} 1.2$ which partially overlaps with the GM130 signal (arrows, a-c). At DIV 6, Na 1.2 signal is stronger and its overlap with GM130 increases (arrows, d-f). Scale bars $=20 \mu \mathrm{m}$.

These processes require a precise distribution of sodium channels accumulated at high densities in discrete subdomains of neuronal membranes. The complete information about the precise molecular and cellular mechanisms for ion channel trafficking and 
compartmentalization into specific neuronal sub-domains, is not yet completely elucidated.

In the present work, we studied the subcellular localization of $\mathrm{Na}_{\mathrm{v}} 1.2$ and $\mathrm{Na}_{\mathrm{v}} 1.7$ VDSC isoforms, in hippocampal neurons, using isoform specific antibodies. We also used a generic antibody $\left(\mathrm{PanNa}_{\mathrm{v}}\right)$ which recognizes, besides $\mathrm{Na}_{\mathrm{v}} 1.2$ and $\mathrm{Na}_{\mathrm{v}} 1.7$, the other $\mathrm{Na}_{\mathrm{v}} 1$ isoforms. In our dissociated neuronal preparations, $\mathrm{PanNa}_{\mathrm{v}}$ antibody immunoreactivity was very strong in the soma and in the AIS.



Figure 5: Analysis of $\mathrm{Na}_{\mathrm{V}} 1.7$ localization in Golgi apparatus. Immunostaining of DIV 2 and DIV 6 hippocampal neurons with $\mathrm{Na}_{\mathrm{V}} 1.7$ antibody (red), GM130 antibody (green) and DAPI (Blue). Localization of $\mathrm{Na}_{\mathrm{V}} 1.7$ is also observed in the soma areas. Arrows indicate the staining for the cis-cisternae of the Golgi apparatus (arrows, a-f). Scale bars $=20 \mu \mathrm{m}$.

In somas we observed a strong staining for $\mathrm{PanNa}_{\mathrm{v}}$ in nuclear areas (data not shown). In agreement with our results, isoforms identified with Pan $\mathrm{Na}_{\mathrm{v}}$ antibody (i.e., $\mathrm{Na}_{\mathrm{v}} 1.1$ ) has been reported to be present in membrane compartments of somas, dendrites and AIS [10,24,25,27,34-38]. Additionally, other studies have shown immunoreactivity for $\mathrm{PanNa}_{\mathrm{v}}$ in the nuclear regions of dissociated cholinergic amacrine cells of mouse retina [39].

It is important to mention that, in our study, the immunoreactivity for $\mathrm{PanNa}_{\mathrm{v}}$ and $\mathrm{Na}_{\mathrm{v}} 1.2$ observed in places of relatively high sodium channel densities, like AIS and soma, might represent pools of newly synthesized channels. Additionally, the amount of functional channel proteins is likely to be related to the amount of channel proteins present in the cytoplasm. However, the immunodetection of the VDSC should not be taken as an indication of the amount of channels inserted into the plasma membrane, but rather like subcellular regions of intense synthesis/trafficking or with limited diffusion (i.e., the AIS) [40].

Now, respect to the presence of VDSC at the AIS, is important to mention that $\mathrm{Na}_{\mathrm{v}} 1.2$ and the isoforms recognized by $\mathrm{PanNa}_{\mathrm{v}}$ antibody, but not $\mathrm{Na}_{\mathrm{v}} 1.7$, were labeled at the AIS, between DIV2 and DIV15. Our results are supported by other studies showing that during early development, $\mathrm{Na}_{\mathrm{v}} 1.2$ was the predominant channel expressed at the AIS. Those studies also reported that, at later developmental stages, other isoform $\left(\mathrm{Na}_{\mathrm{v}} 1.6\right)$ was also detected at the AIS together with $\mathrm{Na}_{\mathrm{v}} 1.2$ [10,40-45], these results are in agreement with the results in the present work showing the expression of VDSC at later stages detected with the PanNa $\mathrm{v}_{\mathrm{v}}$ antibody and might represent other VDSC isoforms. It is very important to mention that sorting of sodium channels to axons and the formation of clusters in the AIS are of primary importance for neuronal electrogenesis. AIS motif may play a fundamental role in controlling the electrical excitability during development and plasticity, since neuronal action potentials are generated in this region due to the presence of VDSC $[3,46,47]$.

On the other hand, our results show that $\mathrm{Na}_{\mathrm{v}} 1.2$ and $\mathrm{Na}_{\mathrm{v}} 1.7$ labeling in soma and proximal dendrites seems to be intracellular, this presumably could represent a pool of newly synthesized $\mathrm{Na}_{\mathrm{v}} 1.2$ and $\mathrm{Na}_{\mathrm{v}} 1.7$ alpha subunits transiting through the rough endoplasmic reticulum and/or Golgi apparatus, prior to subsequent trafficking towards other subcellular compartments (i.e., axons, plasma membrane, etc.). This is evidenced by the expression of these isoforms in soma, areas surrounding the nuclei (likely the ER) and in Golgi. Regarding $\mathrm{Na}_{\mathrm{v}} 1.2$ and $\mathrm{Na}_{\mathrm{v}} 1.7$ localization in the neuronal Golgi, to our knowledge, there are not other studies reporting specifically labeling these isoforms in this organelle in neurons. $\mathrm{Na}_{\mathrm{v}} 1.2$ isoforms were mainly observed in the soma and excluded from the nuclear region and their expression in cell bodies overlapped very well with the labeling for Golgi. The strong $\mathrm{Na}_{\mathrm{v}} 1.2$ labeling in Golgi might suggest a fast and non-limiting transport of these channels from the ER to Golgi.

Additionally, double labeling experiments with $\mathrm{Na}_{\mathrm{v}} 1.7$ and Golgi specific antibodies indicated that the intracellular channels were likely almost exclusively retained within the ER. Regarding the visualization of VDSC in Golgi, there are reports of low levels of a GFP-human heart sodium channel (hH1) which was highly expressed in the ER and to a lesser extend in Golgi of HEK293 cells and cardiac myocytes [48]. In this case, and in our experiments with $\mathrm{Na}_{\mathrm{v}} 1.7$, the ER might serve as a reservoir for the VDSC channels and the transport from the ER to the Golgi apparatus might be among the rate-limiting steps.

On the other hand, our results showing the intense labeling of $\mathrm{Na}_{\mathrm{v}} 1.2$ and $\mathrm{Na}_{\mathrm{v}} 1.7$ within intracellular compartments, and its apparent lower incidence in the cell surface, suggest the presence of a ratelimiting step in the trafficking of these proteins from the ER towards the plasma membrane. Other experiments with transfected cells, reported a low fluorescence signal for $\mathrm{Na}_{\mathrm{v}} 1.7$ in the Golgi apparatus where VDSC become highly glycosylated. This was likely indicating that the processing of newly synthesized channels in the ER or trafficking between the ER and the trans-medial region of the Golgi apparatus, were rate-limiting factors in the cell surface expression of these channels $[49,50]$. Here it is important to mention that, even though our labeling and imaging methods do not allow distinguishing precisely the intracellular from the neuronal surface, we performed labeling experiments with the antibodies for the different sodium channel isoforms, without permeabilization and observed that only was labeled the cell membrane (data not shown). Thus, when we perform the experiments with permeabilization, we were able to distinguish the intracellular compartment from the cellular membrane.

In general, the overall localization of the VDSC studied here is supported by previous findings. Our data for $\mathrm{Na}_{\mathrm{v}} 1.2$ is supported by studies reporting similarities in its localization pattern, in several neuronal populations, including hippocampal neurons [10,25,26,51]. For $\mathrm{Na}_{\mathrm{v}} 1.2$, it is important to mention that the staining that we observed in the proximal regions of some dendrites and localization of $\mathrm{Na}_{\mathrm{v}} 1.2$ in dendrites have been also reported in other studies [26]. Additionally, some apical dendritic $\mathrm{Na}_{\mathrm{v}} 1.2$ staining has been reported in the large pyramidal cells of hippocampal CA1 and layer $\mathrm{V}$ of the neocortex, [24].

On the other hand, is important to mention that findings concerning to $\mathrm{Na}_{\mathrm{v}} 1.2$ localization in axons, have been demonstrated by several studies $[24,26,52]$; however, in our studies with $\mathrm{Na}_{\mathrm{v}} 1.2$, in the 
few cases where we detected some signals in axons, this was very weak. It has been also reported that $\mathrm{Na}_{\mathrm{v}} 1.2$ is predominantly expressed in unmyelinated axons [52]; considering this, our results with $\mathrm{Na}_{\mathrm{v}} 1.2$ might represent unmyelinated axons which probably are not strongly labeled with SMI-35. Indeed, confocal through-focus series experiments with cerebellar granule cells did not detect, or barely detected, specific $\mathrm{Na}_{\mathrm{v}} 1.2$ staining along axons or dendrites [40], which is consistent with our observations for hippocampal neurons.

Regarding our results with $\mathrm{Na}_{\mathrm{V}} 1.7$ labeling, we detected $\mathrm{Na}_{\mathrm{v}} 1.7$ in growth cones and this is reported for the first time in hippocampal neurons. Interestingly, studies in rat retina, demonstrated that regenerating axons and growth cones expressed other sodium channel isoforms. These results, support our findings of $\mathrm{Na}_{\mathrm{v}} 1.7$ localization in growth cones and are indicative that all major voltage-gated ion channels might be expressed in growth cones, suggesting that currents, recorded in these structures are at least partially mediated by sodium channels [45]. Even though $\mathrm{Na}_{\mathrm{v}} 1.7$ has been reported mainly as a peripheral channel, our present results and other studies have shown evidences of its expression within the CNS. For instance, $\mathrm{Na}_{\mathrm{v}} 1.7$ mRNA was detected in hippocampal neurons [16]. Additionally, $\mathrm{Na}_{\mathrm{V}} 1.7$ is present within vasopressin-producing neurons and oxytocinproducing neurons within the rat hypothalamus [19]. Importantly, our results showing $\mathrm{Na}_{\mathrm{v}} 1.7$ labeling in dendrites and axons coincide with results reported in previous studies $[10,26,53,54]$. Other studies have reported presence of $\mathrm{Na}_{\mathrm{v}} 1.7$ in axons of PNS neurons [10,26,54] and growth cones of differentiating NG-108-15 neuroblastoma cells [55].

It is important to mention that the present work might have some significant clinical relevance. Our findings showing the high labeling of $\mathrm{Na}_{\mathrm{V}} 1.2$ in the Golgi could be explored as a potential therapeutic target, for diseases where this isoform is involved. It is known that $\mathrm{Na}_{\mathrm{V}} 1.2$ is a tetrodotoxin (TTX)-sensitive channel which, similar to $\mathrm{Na}_{\mathrm{v}} 1.1$, is preferentially expressed in GABAergic interneurons [23]. Interneurons are crucial elements in the regulation of neuronal network excitability and synchronization of neuronal activity. Missense and loss-offunction mutations in $\mathrm{Na}_{\mathrm{v}} 1.1$ and $\mathrm{Na}_{\mathrm{v}} 1.2$ impair the excitability of GABAergic inhibitory neurons and create neuronal hyperexcitability and several forms of epilepsy. The function of $\mathrm{Na}_{\mathrm{v}} 1.2$ is also involved in the pathophysiology of Multiple Sclerosis (MS), a disease characterized by axonal demyelination and degeneration and consequent cerebellar dysfunction, presumably due to dysregulated immune responses. Thus, $\mathrm{Na}_{\mathrm{v}} 1.2$ channels have been implicated in the restoration to neuronal conduction after demyelination and axonal degeneration [23].

On the other hand, our new findings of $\mathrm{Na}_{\mathrm{v}} 1.7$ at the growth cones will contribute to understanding the nociceptive mechanisms where this channel is involved. Studies on the genetic basis underlying several striking human phenotypes have revealed the importance of human $\mathrm{Na}_{\mathrm{V}} 1.7\left(\mathrm{hNa}_{\mathrm{V}} 1.7\right)$ as an analgesic target [20]. In this sense, $\mathrm{Na}_{\mathrm{V}} 1.7$ specific blockers are under study as potential pain therapeutics which might be expected to have minimal CNS side effects $[21,22]$.

$\mathrm{Na}_{\mathrm{v}} 1.7$ expression in dendrites, axons and growth cones, reported here, may be suggestive of $\mathrm{Na}_{\mathrm{v}} 1.7$ involvement in neurite outgrowth or in the interaction with other molecules to control, either neurite outgrowth, to improve regeneration, or local action potential generation. It will be necessary to determine, in further studies, if sodium channels in growth cones might act as a local signal transducer to mediate precise connections with appropriate target tissues. Interestingly and in support to our findings, it has been mentioned that based on its biophysical properties, $\mathrm{Na}_{\mathrm{v}} 1.7$ is thought to be a threshold channel that is better suited for nerve terminals, where it boots sub- threshold stimuli, rather than at the AIS or nodes of Ranvier [56]. Due to different subcellular localization, our results for $\mathrm{Na}_{\mathrm{v}} 1.2$ and $\mathrm{Na}_{\mathrm{v}} 1.7$ isoforms, point to differential functions, additional to their known roles as action potential generators.

\section{Acknowledgement}

This work was financially supported by Fundacion Instituto de Estudios Avanzados (IDEA) and the Venezuelan Ministry of Science. We thank Veterinary Doctor Emilia Negron and Mr. Javier Mejias for animal care. We are also very grateful to Mrs. Marianela Hernandez for reading of the manuscript and Mrs. Carola Ono for her valuable help in the preparation of the art work.

\section{References}

1. Catterall WA (1992) Cellular and molecular biology of voltage-gated sodium channels. Physiol Rev 72: S15-S48.

2. Golding NL, Kath WL, Spruston N (2001) Dichotomy of action-potential backpropagation in CA1 pyramidal neuron dendrites. J Neurophysiol 86: 2998-3010.

3. Catterall WA (2000) From ionic currents to molecular mechanisms: the structure and function of voltage-gated sodium channels. Neuron 26: 13-25.

4. Catterall WA, Goldin AL, Waxman SG (2005) International Union of Pharmacology. XLVII. Nomenclature and structure-function relationships of voltage-gated sodium channels. Pharmacol Rev 57: 397-409.

5. Denac H, Mevissen M, Scholtysik G (2000) Structure, function and pharmacology of voltage-gated sodium channels. Naunyn Schmiedebergs Arch Pharmacol 362: 453-479.

6. Guy HR, Seetharamulu P (1986) Molecular model of the action potential sodium channel. Proc Natl Acad Sci U S A 83: 508-512.

7. Tabarean IV, Narahashi T (2001) Kinetics of modulation of tetrodotoxinsensitive and tetrodotoxin-resistant sodium channels by tetramethrin and deltamethrin. J Pharmacol Exp Ther 299: 988-997.

8. Tsurubuchi Y, Zhao X, Nagata K, Kono Y, Nishimura K, et al. (2001) Modulation of tetrodotoxin-resistant sodium channels by dihydropyrazole insecticide RH-3421 in rat dorsal root ganglion neurons. Neurotoxicology 22: 743-753.

9. Isom LL, De Jongh KS, Patton DE, Reber BF, Offord J, et al. (1992) Primary structure and functional expression of the beta 1 subunit of the rat brain sodium channel. Science 256: 839-842.

10. Vacher H, Mohapatra DP, Trimmer JS (2008) Localization and targeting of voltage-dependent ion channels in mammalian central neurons. Physiol Rev 88: 1407-1447.

11. Yu EJ, Ko SH, Lenkowski PW, Pance A, Patel MK, et al. (2005) Distinct domains of the sodium channel beta3-subunit modulate channel-gating kinetics and subcellular location. Biochem J 392: 519-526.

12. Goldin AL (2001) Resurgence of sodium channel research. Annu Rev Physiol 63: 871-894.

13. Ogata N, Ohishi $Y$ (2002) Molecular diversity of structure and function of the voltage-gated $\mathrm{Na}+$ channels. Jpn J Pharmacol 88: 365-377.

14. Wu L, Nishiyama K, Hollyfield JG, Wang Q (2002) Localization of Nav1.5 sodium channel protein in the mouse brain. Neuroreport 13:2547-2551.

15. Kerr NCH, Holmes FE, Wynick D (2008) Novel mRNA isoforms of the sodium channels $\mathrm{Na}(\mathrm{v}) 1.2, \mathrm{Na}(\mathrm{v}) 1.3$ and $\mathrm{Na}(\mathrm{v}) 1.7$ encode predicted twodomain, truncated proteins. Neuroscience 155: 797-808.

16. Mechaly I, Scamps F, Chabbert C, Sans A, Valmier J, et al. (2005) Molecular diversity of voltage-gated sodium channel alpha subunits expressed in neuronal and non-neuronal excitable cells. Neuroscience 130: 389-396.

17. Namadurai S, Yereddi NR, Cusdin FS, Huang CLH, Chirgadze DY, et al (2015) A new look at sodium channel $\beta$ subunits. Open Biol 5: 140192. 
18. Bao L (2015) Trafficking regulates the subcellular distribution of voltagegated sodium channels in primary sensory neurons. Mol Pain 11: 61.

19. Black JA, Hoeijmakers JGJ, Faber CG, Merkies ISJ, Waxman SG, et al. (2013) NaV1.7: stress-induced changes in immunoreactivity within magnocellular neurosecretory neurons of the supraoptic nucleus. Mol Pain 9: 39.

20. Dib-Hajj SD, Yang Y, Black JA, Waxman SG (2013) The Na(V)1.7 sodium channel: from molecule to man. Nat Rev Neurosci 14: 49-62.

21. Green BR, Bulaj G, Norton RS (2014) Structure and function of $\mu$ conotoxins, peptide-based sodium channel blockers with analgesic activity. Future Med Chem 6: 1677-1698.

22. Chow CY, Cristofori-Armstrong B, Undheim EAB, King GF, Rash LD, et al. (2015) Three Peptide Modulators of the Human Voltage-Gated Sodium Channel 1.7, an Important Analgesic Target, from the Venom of an Australian Tarantula. Toxins 7: 2494-2513.

23. De Lera Ruiz M, Kraus RL (2015) Voltage-Gated Sodium Channels: Structure, Function, Pharmacology, and Clinical Indications. J Med Chem 58: 7093-7118.

24. Gong B, Rhodes KJ, Bekele-Arcuri Z, Trimmer JS (1999) Type I and type II $\mathrm{Na}(+)$ channel alpha-subunit polypeptides exhibit distinct spatial and temporal patterning, and association with auxiliary subunits in rat brain. J Comp Neurol 412: 342-352.

25. Westenbroek RE, Merrick DK, Catterall WA (1989) Differential subcellular localization of the RI and RII Na+ channel subtypes in central neurons. Neuron 3: 695-704.

26. Ahn M, Beacham D, Westenbroek RE, Scheuer T, Catterall WA (2007) Regulation of $\mathrm{Na}(\mathrm{v}) 1.2$ channels by brain-derived neurotrophic factor, TrkB, and associated Fyn kinase. J Neurosci Off J Soc Neurosci 27: 11533-11542.

27. Lorincz A, Nusser Z (2008) Cell-type-dependent molecular composition of the axon initial segment. J Neurosci Off J Soc Neurosci 28: 14329-14340.

28. Boiko T, Rasband MN, Levinson SR, Caldwell JH, Mandel G, et al. (2001) Compact myelin dictates the differential targeting of two sodium channel isoforms in the same axon. Neuron 30: 91-104.

29. Boiko T, Van Wart A, Caldwell JH, Levinson SR, Trimmer JS, et al. (2003) Functional specialization of the axon initial segment by isoform-specific sodium channel targeting. J Neurosci Off J Soc Neurosci 23: 2306-2313.

30. Correa G, Longart M (2010) [Morphometric analysis of the differentiation process of hippocampal neurons in vitro]. Investig Clínica 51: 501-518.

31. Longart M, Liu Y, Karavanova I, Buonanno A (2004) Neuregulin-2 is developmentally regulated and targeted to dendrites of central neurons. J Comp Neurol 472: 156-172.

32. Duflocq A, Chareyre F, Giovannini M, Couraud F, Davenne M (2011) Characterization of the axon initial segment (AIS) of motor neurons and identification of a para-AIS and a juxtapara-AIS, organized by protein 4.1B. BMC Biol 9: 66

33. Pennypacker K, Fischer I, Levitt P (1991) Early in vitro genesis and differentiation of axons and dendrites by hippocampal neurons analyzed quantitatively with neurofilament- $\mathrm{H}$ and microtubule-associated protein 2 antibodies. Exp Neurol 111: 25-35.

34. Chung YH, Joo KM, Kim MJ, Cha CI (2003) Age-related changes in the distribution of $\mathrm{Na}(\mathrm{v}) 1.1$ and $\mathrm{Na}(\mathrm{v}) 1.2$ in rat cerebellum. Neuroreport 14: 841-845.

35. Inda MC, DeFelipe J, Muñoz A (2006) Voltage-gated ion channels in the axon initial segment of human cortical pyramidal cells and their relationship with chandelier cells. Proc Natl Acad Sci U S A 103: 2920-2925.

36. Lorincz A, Nusser Z (2010) Molecular identity of dendritic voltage-gated sodium channels. Science 328: 906-909.

37. Vega-Saenz de Miera EC, Rudy B, Sugimori M, Llinás R (1997) Molecular characterization of the sodium channel subunits expressed in mammalian cerebellar Purkinje cells. Proc Natl Acad Sci U S A 94: 7059-7064.
38. Van Wart A, Trimmer JS, Matthews G (2007) Polarized distribution of ion channels within microdomains of the axon initial segment. J Comp Neurol 500: 339-352.

39. Kaneda M, Ito K, Morishima Y, Shigematsu Y, Shimoda Y, et al. (2007) Characterization of voltage-gated ionic channels in cholinergic amacrine cells in the mouse retina. J Neurophysiol 97: 4225-4234.

40. Osorio N, Alcaraz G, Padilla F, Couraud F, Delmas P, et al. (2005) Differential targeting and functional specialization of sodium channels in cultured cerebellar granule cells. J Physiol 569: 801-816.

41. Garrido JJ, Fernandes F, Moussif A, Fache MP, Giraud P, et al. (2003) Dynamic compartmentalization of the voltage-gated sodium channels in axons. Biol Cell Auspices Eur Cell Biol Organ 95: 437-445.

42. Garrido JJ, Giraud P, Carlier E, Fernandes F, Moussif A, et al. (2003) A targeting motif involved in sodium channel clustering at the axonal initial segment. Science 300: 2091-2094.

43. Komada M, Soriano P (2002) [Beta]IV-spectrin regulates sodium channel clustering through ankyrin-G at axon initial segments and nodes of Ranvier. J Cell Biol 156: 337-348.

44. Kuba H, Ohmori H (2009) Roles of axonal sodium channels in precise auditory time coding at nucleus magnocellularis of the chick. J Physiol 587: $87-100$

45. Kuba H, Oichi Y, Ohmori $\mathrm{H}$ (2010) Presynaptic activity regulates $\mathrm{Na}(+)$ channel distribution at the axon initial segment. Nature 465: 1075-1078.

46. Martínez-Hernández J, Ballesteros-Merino C, Fernández-Alacid L Nicolau JC, Aguado C, et al. (2013) Polarised localisation of the voltagegated sodium channel $\mathrm{Na}(\mathrm{v}) 1.2$ in cerebellar granule cells. Cerebellum Lond Engl 12: 16-26.

47. Stuart G, Schiller J, Sakmann B (1997) Action potential initiation and propagation in rat neocortical pyramidal neurons. J Physiol 505: 617-632.

48. Zimmer T, Biskup C, Dugarmaa S, Vogel F, Steinbis M, et al. (2002) Functional expression of GFP-linked human heart sodium channel (hH1) and subcellular localization of the a subunit in HEK293 cells and dog cardiac myocytes. J Membr Biol 186: 1-12.

49. Schmidt JW, Catterall WA (1986) Biosynthesis and processing of the alpha subunit of the voltage-sensitive sodium channel in rat brain neurons. Cell 46: 437-444.

50. Schmidt JW, Catterall WA (1987) Palmitylation, sulfation, and glycosylation of the alpha subunit of the sodium channel. Role of posttranslational modifications in channel assembly. J Biol Chem 262 13713-13723.

51. Cantrell AR, Catterall WA (2001) Neuromodulation of Na+ channels: an unexpected form of cellular plasticity. Nat Rev Neurosci 2: 397-407.

52. Westenbroek RE, Noebels JL, Catterall WA (1992) Elevated expression of type II Na+ channels in hypomyelinated axons of shiverer mouse brain. J Neurosci Off J Soc Neurosci 12: 2259-2267.

53. Feigenspan A, Dedek K, Schlich K, Weiler R, Thanos S, et al. (2010) Expression and biophysical characterization of voltage-gated sodium channels in axons and growth cones of the regenerating optic nerve. Invest Ophthalmol Vis Sci 51: 1789-1799.

54. Weiss J, Pyrski M, Jacobi E, Bufe B, Willnecker V, et al. (2011) Loss-offunction mutations in sodium channel Nav1.7 cause anosmia. Nature 472: 186-190.

55. Kawaguchi A, Asano H, Matsushima K, Wada T, Yoshida S, et al. (2007) Enhancement of sodium current in NG108-15 cells during neural differentiation is mainly due to an increase in NaV1.7 expression. Neurochem Res 32: 1469-1475.

56. Rush AM, Cummins TR, Waxman SG (2007) Multiple sodium channels and their roles in electrogenesis within dorsal root ganglion neurons. J Physiol 579: 1-14. 